\title{
CATEGORIZING THE AGE GROUP AND MEASURING ACCURACY OF FUZZY MODEL
}

\author{
Moka Uma Devi \\ Research Scholar, Department of CSE, \\ Acharya Nagarjuna University, Andhra Pradesh, India \\ Dr. Uppu Ravi Babu \\ Professor, Dept. of CSE, \\ DRK College of Engineering \& Tech, Hyderabad, India
}

\begin{abstract}
The age group estimation can be done in many methods for each and every step in the process. To estimate the age group we can perform many methods for each and every step. In our proposed method we are estimating the age group after extracting the features in any one of the method and derives an algorithm. Based on that algorithm we created fuzzy model to classify the dataset and predict the age. In our paper the performance of fuzzy model is also evaluated. The different applications of age estimation are law enforcement, biometrics, security control, human computer interaction, crime detection.
\end{abstract}

Keywords: Fuzzy Model, Age Estimation, Feature Extraction, Prediction.

Cite this Article: Moka Uma Devi and Dr. Uppu Ravi Babu, Categorizing the Age Group and Measuring Accuracy of Fuzzy Model, International Journal of Electronics and Communication Engineering and Technology, 10(5), 2019, pp. 23-35.

$\mathrm{http}$ ///iaeme.com/Home/issue/IJECET?Volume=10\&Issue $=5$

\section{INTRODUCTION}

There is many methods to extract the key features from each database After extracting the face features from facial image the labelling of the age can be done by a class or by a set of sequential values. If the labelling is done through a class then it is solved through classification otherwise it is solved through regression. In our paper we are classifying, predicting and evaluating our proposed fuzzy model to estimate the age. The brief process is based on the derived algorithm first we split the data in to two subsets i.e. training data and test data by using stratified cross validation method. By using training data and test data we are classifying or predicting the age group using Fuzzy model and evaluation measures are considered by using confusion matrix. We can estimate the age through multi class classification or regression or a combination of both classification and regression. In fuzzy model after defining the membership function and deciding the descriptors our proposed model can categorize the age group. 
After defining the membership function we can establish the relation between input variable and output variable Then after forming the rule based we can evaluate the rules and then we can evaluate the strong rule.

\section{LITERATURE SURVEY}

\subsection{Identification of the Facial Skin Region}

Identify the skin region by using Hue Saturation Value colour model. We can identify the skin pixels by using the formulas of HSV model and Convert the skin region of RGB image into Grey scale image

\subsection{Counting the Transition Count}

With the help of 5 X5 window extract the features of the image by identifying any one of the patterns or by local binary pattern, local direction pattern, and Local Ternary pattern. The extracted feature is in binary value. With that binary value we can count 0 transitions, 2 transitions, 4 transitions

\subsection{Derive an Algorithm}

By analysing the transition count of different facial image databases we can derive an algorithm

\subsection{Data Splitting Methods}

There are different data splitting methods. They are

a) Cross-Validation (CV) b) Bootstrap and Monte-Carlo Cross-Validation (MCCV)

c) Bootstrapped Latin Partition (BLP) d) Kennard-Stone algorithm (K-S) and Sample Set Partitioning Based on Joint $X-Y$ Distances Algorithm (SPXY). Our present research work uses Stratified cross validation is used to split train dataset and test dataset some different types of Cross Validation are

- Leave One Out Cross Validations (LOOCV)

- $\quad$ k-fold cross-validation

- Stratified Cross Validation

- Time Series cross validation

Our research paper works on Stratified Cross Validation to split the dataset into training dataset and test dataset

\subsubsection{Stratified Cross Validation}

It is similar to K-fold cross validation. Only difference is select that 25 data points such that it covers all classes belong to our dataset points. Similarly we have to perform 5 experiments on our 100 dataset points by selecting different 25 dataset points which includes all different class type instances.

\subsection{Fuzzy Classifier}

The classifier is an algorithm that classifies the given data and label to an object and also predicts the given tuple belongs to which class label. Feature vector describes the object descriptor. 


\subsubsection{Fuzzy Membership Function}

Consider a Fuzzy set $\mathrm{A}$ where the set is determined as $\{(\mathrm{x}, \mathrm{m}(\mathrm{x})) \mid \mathrm{x} \in X\}$ where $\mathrm{x}$ is an element, $\mathrm{m}(\mathrm{x})$ is the membership function of set $\mathrm{A}$ and $\mathrm{X}$ is the universe of discourse. In fuzzy sets each element is mapped by membership function within the interval $[0,1]$ which can be represented as $\mathrm{m}(\mathrm{x}): \mathrm{X}[0,1], \rightarrow$ where

$M(x)=1$ if $x$ is totally in $A ; \quad M(x)=0$ if $x$ is not in $A ; 0<M(x)<1$ if $x$ is partly in A;

There are many fuzzy membership functions. Among them our research paper uses Triangular membership function

\subsubsection{Triangular Membership Function}

Let $\mathrm{a}, \mathrm{b}, \mathrm{c}$ are the three vertices to represent the $\mathrm{x}$-coordinate of $\mathrm{m}(\mathrm{x})$ in fuzzy set A.

a- lower boundary where membership degree is zero

c- upper boundary where membership degree is zero

b-the centre where membership degree is one

$\mathrm{m}(\mathrm{x})=0$ if $\mathrm{x}<=\mathrm{a} ; \mathrm{m}(\mathrm{x})=(\mathrm{x}-\mathrm{a}) /(\mathrm{b}-\mathrm{a})$ if $\mathrm{a}<=\mathrm{x}<=\mathrm{b} ; \mathrm{m}(\mathrm{x})=(\mathrm{c}-\mathrm{x}) /(\mathrm{c}-\mathrm{b})$ if $\mathrm{b}<=\mathrm{x}<=\mathrm{c} ; \mathrm{m}(\mathrm{x})=0$ if $\mathrm{x}>=\mathrm{c}$;

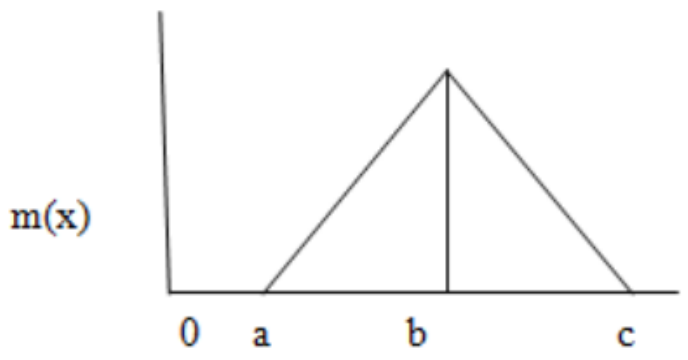

Figure 1 Triangular Membership Function

\subsection{The Confusion Matrix for Multiple Classes}

To evaluate the performance of our fuzzy model we are using confusion matrix for multiple classes. The confusion matrix is a matrix where columns represent the predicted classes and rows represent the actual classes. The diagonal values are True Positive values for their respective class. The confusion matrix is used to measure the model performance. We are using Accuracy, Precision, Recall, F1 score are the performance measures based on confusion matrix. To select one of the models we have to use one of the performance measure based on the dataset points. To calculate those performance methods we have to know about the following terms

1) True Positive: True Positive (TP) are the values which are correctly identified for each class i.e. When both actual class of the data point and the predicted was true.

2) True Negatives: True Negatives (TN) are correctly rejected for a given class i.e. when both actual class of the data point and the predicted was false.

3) False Positives: False Positives (FP) are incorrectly identified for certain class i.e. when the actual class of the data point is false and predicted as true

4) False Negatives: False Negatives (FN) are incorrectly rejected for certain class i.e. when actual class of the data point was true and predicted as false. 
The performance measures based on confusion matrix are

\subsubsection{Accuracy}

It is calculated as total no of correct predictions divided by total number of data points Accuracy $=\mathrm{TP}_{\mathrm{A}}+\mathrm{TP}_{\mathrm{B}}+\ldots \ldots . . \mathrm{TP}_{\mathrm{N}} /$ (total no of data points).

\subsubsection{Precision}

The output of the precision is it returns only relevant instances of a given model. The formula of the precision for a given class $\mathrm{A}$ is

Precision $\mathrm{P}(\mathrm{A})=\mathrm{TP}_{\mathrm{A}} /\left(\mathrm{TP}_{\mathrm{A}}+\mathrm{FP}_{\mathrm{A}}\right)$.

So Average Precision $=\mathrm{P}(\mathrm{A})+\mathrm{P}(\mathrm{B})+\ldots \ldots .+\mathrm{P}(\mathrm{N}) / \mathrm{N}$

\subsubsection{Recall or Sensitivity}

The output of the sensitivity is to identify all relevant instances. The formula of the sensitivity for a given class $\mathrm{A}$ is

Recall R $(\mathrm{A})=\mathrm{TP}_{\mathrm{A}} /\left(\mathrm{TP}_{\mathrm{A}}+\mathrm{FN}_{\mathrm{A}}\right)$. So Average Recall $=\mathrm{R}(\mathrm{A})+\mathrm{R}(\mathrm{B})+\ldots+\mathrm{R}(\mathrm{N}) / \mathrm{N}$.

\subsubsection{F1 Score}

The output of the F1 score is the harmonic mean of recall and precision. Single metric that combines recall and precision using the harmonic mean

F1 Score $=$ Harmonic Mean (Precision, Recall)

F1 Score $=2 *$ Precision $*$ Recall $/($ Precision + Recall $)$

\section{PROPOSED METHOD}

Our proposed method is designed into two portions. The first portion tells us about inputting the each input image at a time .The second portion tells us about inputting the set of facial database images

\subsection{First Portion}

Step1.Input the original face image

Step2. Identify the skin region of face

Step3. Now convert the RGB face image into grey scale image.

Step4. Extract the features of the image by using the following methods. Those are two types of methods. First method consists of the following methods a) LBP method b) LTP method c) LDP method. Second method consists of the following patterns a) V and Inverted V pattern b)Diamond pattern c)Right angular and left angular Pattern

Step5.Count the number of 0 transitions and also count the number of 4 transitions for the given image

\subsection{Second Portion}

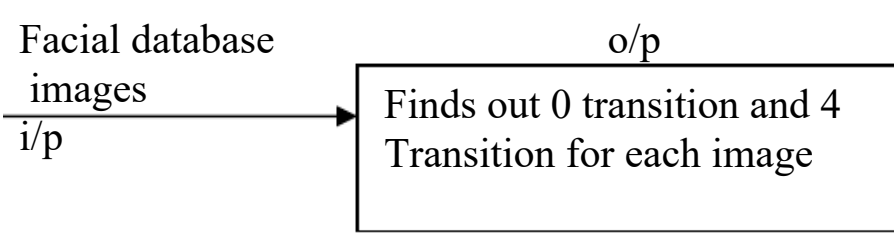

FIRST PORTION



OUTPUT DATABASE

Figure 2 Block diagram, of proposed method 
Step1.The five different types of databases are given as input to the first portion one by one.

Step2. The output of the FIRSTPORTION is the database which contains the output of each and every image

Step 3.The database is split into two datasets .One is training dataset and other is Test data set by using Stratified cross validation method.

Step 4.With the analysis of training dataset we can derive an algorithm.

Step5.For that derived algorithm we have to detect what are the inputs and outputs

Step 6.By using the inputs and outputs of an algorithm we are creating Fuzzy model

Step7.Now the fuzzy model is validated by taking each Test data set as an input

Step8.The Fuzzy model is evaluated its performance by calculating the F1 score and Accuracy.

\subsection{Fuzzy Model}

\section{$(0+4)$ transition count}

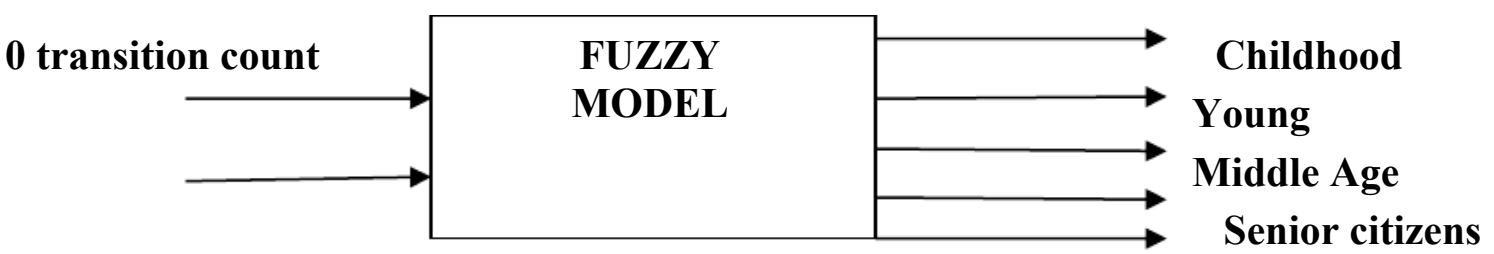

Figure 2 Block diagram

Table 1 Rule based form resultant Matrix

\begin{tabular}{|c|c|c|c|c|c|}
\hline AGE & VS & S & M & L & VL \\
\hline VS & Senior & Middle & Child & $\begin{array}{c}\text { Senior } \\
\text { Citizen }\end{array}$ & Child \\
\hline S & Senior & Middle & $\begin{array}{c}\text { Senior } \\
\text { Citizen }\end{array}$ & Young & Young \\
\hline M & Middle & Middle & $\begin{array}{c}\text { Senior } \\
\text { Citizen }\end{array}$ & $\begin{array}{c}\text { Senior } \\
\text { Citizen }\end{array}$ & Young \\
\hline L & Senior & Middle & Middle & $\begin{array}{c}\text { Senior } \\
\text { Citizen }\end{array}$ & Young \\
\hline VL & Senior & Middle & $\begin{array}{c}\text { Senior } \\
\text { Citizen }\end{array}$ & $\begin{array}{c}\text { Senior } \\
\text { Citizen }\end{array}$ & Young \\
\hline
\end{tabular}

Membership function for (0) transition count for first input variable(x):

$\begin{array}{llll}\mathrm{VS}(0) & \mathrm{S}(0) & \mathrm{M}(0) & \mathrm{L}(0) \\ \mathrm{VL}(0)\end{array}$

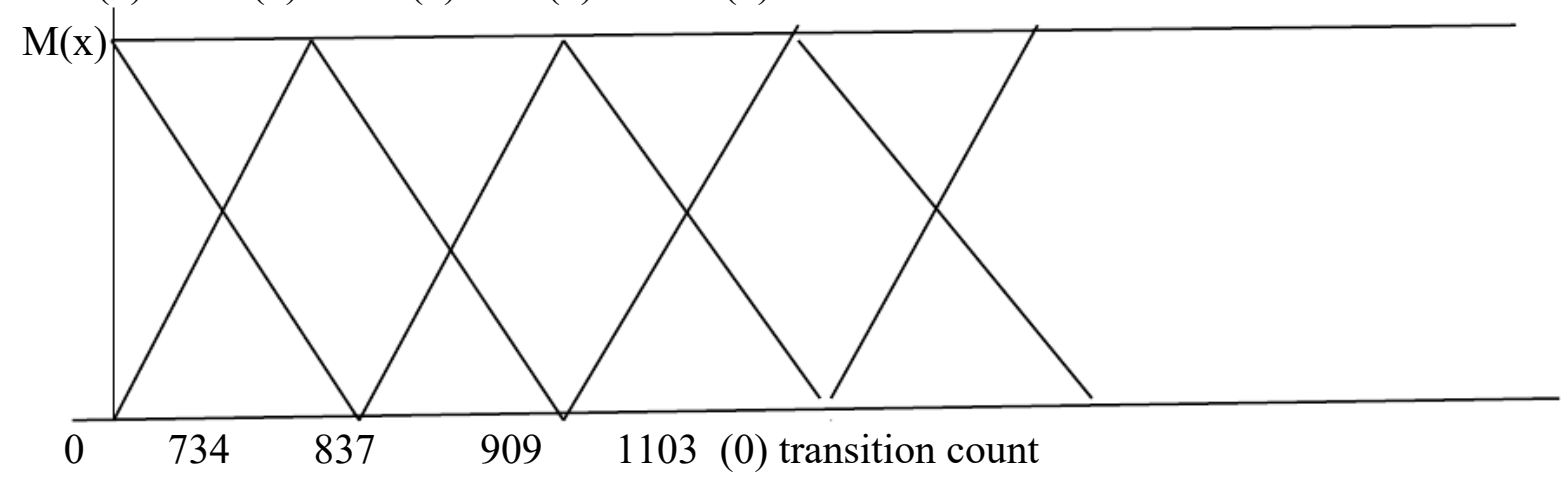


(1). $\mathrm{M}_{\mathrm{vs}(0)}(\mathrm{X})=(734-\mathrm{x}) / 734$ if $0<=\mathrm{x}<=734 ;(2) \cdot \mathrm{M}_{\mathrm{s}(0)}(\mathrm{X})=(\mathrm{x}-0) / 734$ if $0<=\mathrm{x}<=734 \&(837-$ $\mathrm{x}) /(837-734)$ if $734<=\mathrm{x}<=837 ; 3 \cdot \mathrm{M}_{\mathrm{M}(0)}(\mathrm{X})=(\mathrm{x}-734) /(837-734)$ if $734<=\mathrm{x}<=837$ and $(909-\mathrm{x}) /$ $909-837$ if $837<=\mathrm{x}<=909 ; 4 . \mathrm{M}_{\mathrm{L}(0)}(\mathrm{X})=(\mathrm{x}-837) /(909-837)$ if $837<=\mathrm{x}<=909$ and $(1103-\mathrm{x}) /(1103-$ 909)if $909<=\mathrm{x}<=1103 ; 5 . \mathrm{MvL}(0)(\mathrm{X})=(\mathrm{x}-909) /(1103-909)$ if $909<=\mathrm{x}<=1103$

Membership function for the (0+4) transitions for second input variable(y)

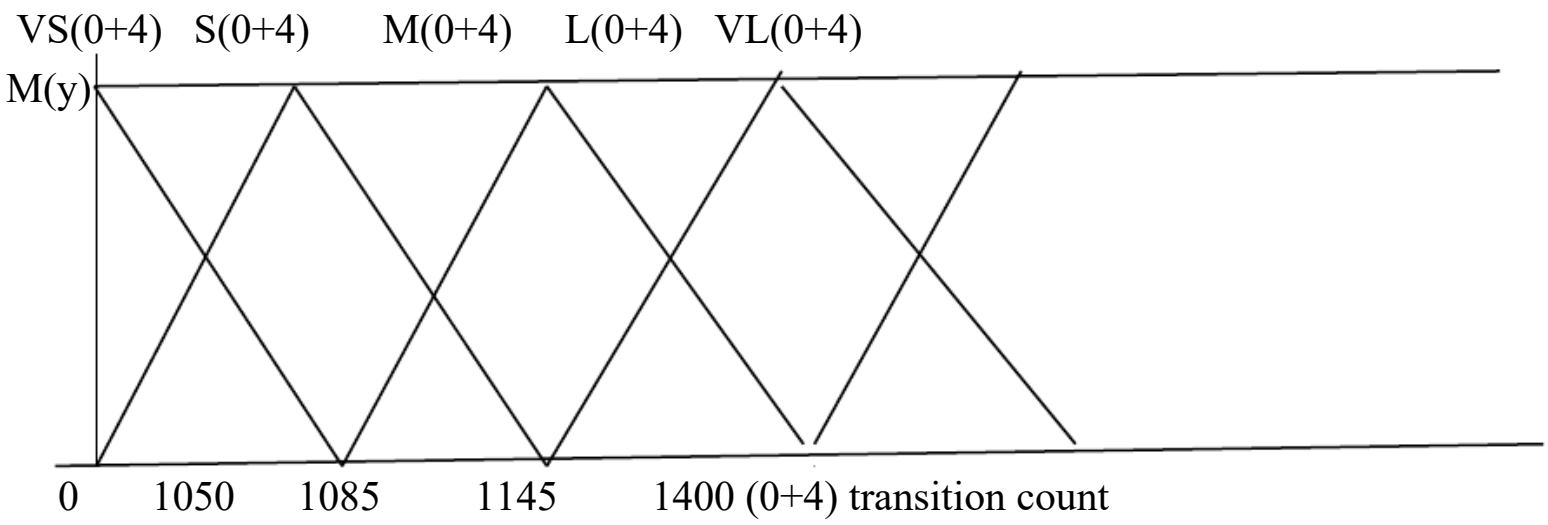

$1 . \operatorname{Mvs}(0+4)(y)=(1050-y) / 1050$ if $0<=y<=1050$

$2 . \mathrm{M}_{\mathrm{S}(0+4)}(\mathrm{y})=(\mathrm{y}-0) / 1050$ if $0<=\mathrm{y}<=1050$ and $(1085-\mathrm{y}) /(1085-1050)$ if $1050<=\mathrm{y}<=1085$

3. $\mathrm{M}_{\mathrm{M}(0+4)}(\mathrm{y})=(\mathrm{y}-1050) /(1085-1050)$ if $1050<=\mathrm{y}<=1085$

$=(1145-\mathrm{y}) / 1145-1085$ if $1085<=\mathrm{y}<=1145$

$4 \mathrm{M}_{\mathrm{L}(0+4)}(\mathrm{y})=(\mathrm{y}-1085) /(1145-1085)$ if $1085<=\mathrm{y}<=1145$

$(1400-\mathrm{x}) /(1400-1145)$ if $1145<=\mathrm{y}<=1400$

5. $\operatorname{MvL}(0+4)(y)=(y-1145) /(1400-1145)$ if $1145<=y<=1400$

\section{Membership function for Age group category for output variable (z)}

Different age group categories are 1.Childhood 2.young Age (13-25years)

3. Middle age (26-40years) 4. Senior age (40-60years) 5.Senior Citizens (more than 60 years

$1 . \mathrm{M}_{\text {childhood }}(\mathrm{z})=(13-\mathrm{z}) / 13$ if $0<=\mathrm{z}<=13$;

(2). $M_{\text {young }}(\mathrm{z})=(\mathrm{z}-0) / 13$ if $0<=\mathrm{z}<=13 ; \quad(26-\mathrm{z}) /(26-13)$ if $13<=\mathrm{z}<=26$;

(3). $\mathrm{M}_{\text {Middle }}(\mathrm{z})=(\mathrm{z}-13) /(26-13)$ if $13<=\mathrm{z}<=26 ; \quad=(40-\mathrm{z}) / 40-26$ if $26<=\mathrm{z}<=40$;

(4). $M$ Seniors $(z)=(z-26) /(40-26)$ if $26<=\mathrm{z}<=40$

$(80-z) /(80-40)$ if $40<=z<=80$;

5. $M_{\text {Senior citizens }}(\mathrm{z})=(\mathrm{z}-40) /(80-40)$ if $40<=\mathrm{z}<=80$

childhood young middle age Senior age Senior Citizen

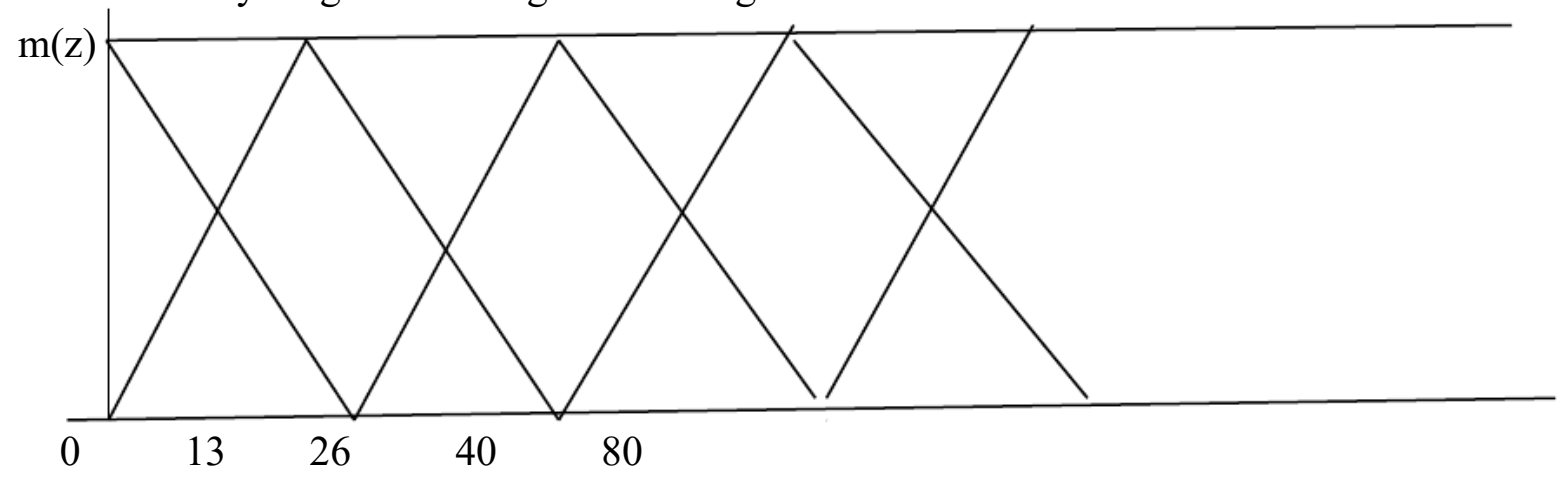




\section{RESULTS AND DISCUSSION}

Table 2 Membership function for 0 transition \& $(0+4)$ transitions

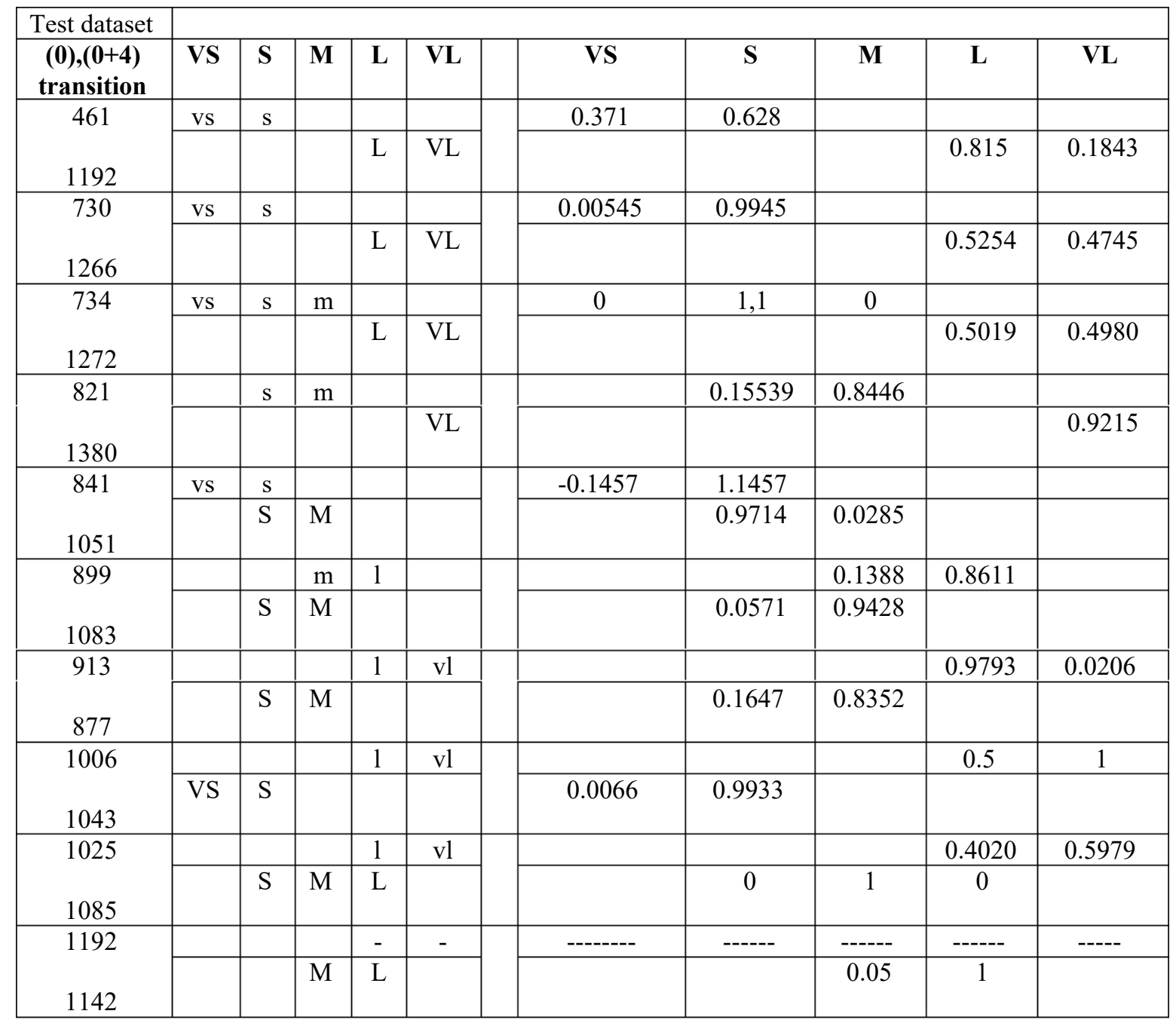

\subsection{Form a Rule Base and Evaluate the Rules in the Table}

From the above table we are calculating the membership function values(vs, s, m, 1, vl) for 0 transition count and also calculating membership function values(VS,S,M,L,VL) for $(0+4)$ transition count. Some functions evaluate very small and small membership functions and some functions evaluate medium, large, very large membership functions. Based on those values different rules are generated for each and every dataset.

After generating the rules for each data set the maximum value is considered. That value is used to calculate the output value.

\section{Resultant Matrix}

The above model is to categorize the age groups by taking the training dataset as an input. The above model produces the resultant matrix as shown below by using the above model. we will find out the membership functions for input variables for $(0)$ transitions and $(0+4)$ transitions. Next we substitute each and every test data set values in those membership functions 
Table 3 Strength rules for each dataset.

\begin{tabular}{|c|c|c|c|c|c|c|c|}
\hline $\begin{array}{c}\operatorname{Lac}(0) \\
\operatorname{Rac}(0+4)\end{array}$ & R1 & R2 & R3 & R4 & R5 & R6 & MAX \\
\hline $\begin{array}{c}461 \\
1192 \\
\end{array}$ & 0.37 & 0.1843 & 0.628 & 0.1843 & & & 0.628 \\
\hline $\begin{array}{r}730 \\
1266\end{array}$ & 0.0054 & 0.0054 & 0.5254 & 0.4745 & & & 0.5254 \\
\hline $\begin{array}{r}734 \\
1272 \\
\end{array}$ & 0 & 0 & 0.5019 & 0.4980 & 0 & 0 & 0.5019 \\
\hline $\begin{array}{l}821 \\
1380 \\
\end{array}$ & 0.8446 & 0.1553 & & & & & 0.8446 \\
\hline $\begin{array}{r}841 \\
1051\end{array}$ & -0.1457 & -0.1457 & 0.9714 & 0.0285 & & & 0.9714 \\
\hline $\begin{array}{r}899 \\
1083 \\
\end{array}$ & 0.0571 & 0.1388 & 0.0571 & 0.8611 & & & 0.8611 \\
\hline $\begin{array}{r}913 \\
877 \\
\end{array}$ & 0.1647 & 0.8352 & 0.0206 & 0.0206 & & & 0.8352 \\
\hline $\begin{array}{l}1006 \\
1043 \\
\end{array}$ & 0.0066 & 0.5 & 0.0066 & 0.9933 & & & 0.9933 \\
\hline $\begin{array}{l}1025 \\
1085\end{array}$ & 0 & 0.4020 & 0 & 0 & 0.5979 & 0 & 0.597 \\
\hline $\begin{array}{l}1192 \\
1142 \\
\end{array}$ & 1 & & & & & & 1 \\
\hline
\end{tabular}

\subsection{Calculate $Z$ Value}

The $\mathrm{z}$ value is calculated by taking the maximum value of the above table and equalizing that value to the output membership functions. Then we can predict particular age for each and every data set .we is obtaining the $\mathrm{z}$ value by using defuzzification technique.

Table 4 Predicting age by Deffuzification

\begin{tabular}{|c|c|c|c|}
\hline $\begin{array}{c}\text { Lac (0) } \\
\text { Rac(0+4) }\end{array}$ & Z Vaue & $\begin{array}{c}\text { Predicted } \\
\text { Age Group }\end{array}$ & $\begin{array}{c}\text { Actual } \\
\text { Age group }\end{array}$ \\
\hline 461 & 12.775 & Child & child \\
1192 & 13 & Young/child & child \\
\hline 730 & 13 & Young/child & young \\
1266 & 13 & Young/child & young \\
\hline 734 & 26.0143 & Middle/senoirs & Middle age \\
\hline 1272 & & & \\
\hline 841 & & & \\
\hline
\end{tabular}




\begin{tabular}{|c|c|c|c|}
\hline $\begin{array}{c}\text { Lac (0) } \\
\mathbf{R a c}(\mathbf{0}+\mathbf{4})\end{array}$ & Z Vaue & $\begin{array}{c}\text { Predicted } \\
\text { Age Group }\end{array}$ & $\begin{array}{c}\text { Actual } \\
\text { Age group }\end{array}$ \\
\hline 899 & 26.0695 & Middle/Seniors & Middle age \\
1083 & 73.408 & Seniors/senior citizen & Seniors \\
\hline 913 & 40 & & Seniors \\
877 & & Seniors & Senior citizen \\
\hline 1006 & 63.916 & Seniors/seniorcitizens & Senior citizen \\
\hline 1043 & & & \\
\hline 1025 & 80 & seniorcitizen & \\
\hline 1192 & & & \\
\hline
\end{tabular}

$\mathrm{FN}(1)=0 ; \mathrm{FN}(2)=0 ; \mathrm{FN}(3)=0 ; \mathrm{FN}(4)=0 ; \mathrm{FN}(5)=0$

Table 5 Confusion Matrix

\begin{tabular}{|c|c|c|c|c|c|c|}
\hline & Child & Young & $\begin{array}{c}\text { Middle } \\
\text { Age }\end{array}$ & Senior & $\begin{array}{c}\text { Senior } \\
\text { Citizen }\end{array}$ & Total \\
\hline Child & 2 & 0 & 0 & 0 & 0 & 2 \\
\hline Young & 0 & 2 & 0 & 0 & 0 & 2 \\
\hline $\begin{array}{c}\text { Mid } \\
\text { Age }\end{array}$ & 0 & 0 & 2 & 0 & 0 & 2 \\
\hline Senior & 0 & 0 & 0 & 2 & 0 & 2 \\
\hline $\begin{array}{c}\text { Senior } \\
\text { Citizen }\end{array}$ & 0 & 0 & 0 & 0 & 2 & 2 \\
\hline Total & 2 & 2 & 2 & 2 & 2 & 10 \\
\hline
\end{tabular}

$\mathrm{TP}=2 ; \quad \mathrm{TP}=2 ; \quad \mathrm{TP}=2 ; \mathrm{TP}=2 ; \quad \mathrm{TP}=2$

$\mathrm{FP}=0 ; \mathrm{FP}=0 ; \mathrm{FP}=0 ; \mathrm{FP}=0 ; \mathrm{FP}=0$

$\mathrm{P}(1)=1 ; \mathrm{P}(2)=0.666 ; \mathrm{P}(3)=1 ; \mathrm{P}(4)=1 ; \mathrm{P}(5)=1$

\subsection{Confusion Matrix for Multiclass}

From the above table we can find out the accuracy model by using confusion matrix .The fuzzy model not gives us the boundary value, instead it gives us the range value. So for any fuzzy models hoping it gives us the cent percent accurate value if our rule based assumption is cent percent correct

\subsection{Different Performance Measures}

1) ACCURACY: For balanced data accuracy gives good results. If accuracy is high our model is good. But finding out the accuracy for imbalanced data misleads performance. The TP gives us correct classifications.

Accuracy $=\mathrm{TP} 1+\mathrm{TP} 2+\mathrm{TP} 3+\mathrm{TP} 4+\mathrm{TP} 5 /($ Total no of Classifications $)$

$$
=2+2+2+2+2 / 10=9 / 10=1
$$




\section{2) PRECISION:}

precision $($ Class 1$)=\mathrm{P}(1)=\mathrm{TP} 1 /(\mathrm{TP} 1+\mathrm{FP} 1)$

$\mathrm{P}(1)=2 / 2+0=1 ; \mathrm{p}(2)=2 / 2+0=1 ;$

$\mathrm{P}(3)=2 / 2+0=1 ; \quad \mathrm{P}(4)=2 / 2=1 ; \quad \mathrm{P}(5)=2 / 2=1$;

So Average Precision $=(1+1+1+1+1) / 5=1$

\section{3)RECALL:}

$\operatorname{Recall}($ Class 1$)=\mathrm{R}(1)=\mathrm{TP} 1 /(\mathrm{TP} 1+\mathrm{FN} 1)$

$\mathrm{R}(1)=2 / 2+0=1 ; \quad \mathrm{R}(2)=2 / 2+0=1 ; \mathrm{R}(3)=2 / 2=1 ;$

$\mathrm{R}(4)=2 / 2=1 ; \mathrm{R}(5)=2 / 2=1 ;$ SoAverage Recall $=(1+1+1+1+1) / 5=1$

\section{4) F1 SCORE:}

F1 score $=2 *$ Precision $*$ Recall $/($ Precision + Recall $)$

$=2 * 1 * 1 /(1+1)$;

$=1$

\section{CONCLUSION}

The present paper evaluates the performance of our Fuzzy model from 0 transition count and $0+4$ transition count. The Fuzzy model classifies the data and predicts the dataset. The accuracy of our proposed research work is $100 \%$ if our assumption table which is derived from algorithm is accurate. The Fuzzy model doesn't gives us boundary value rather it specifies the range of the value. So the models created by using fuzzy model produce excellent accuracy if our rule based assumption is accurate. The F1 score value for our proposed model is 1 . The accuracy value for our model is good when the dataset in confusion matrix is balanced data. For imbalanced data the F1 score is the perfect measure. In Future we can use Fuzzy model as a classifier and predictor for not only in age grouping but also in other problems which we can categories.

\section{REFERENCES}

[1] Dubois, D., and Prade, H. (Eds.), Fundamentals of Fuzzy Sets. The Handbook of Fuzzy Sets Series. Kluwer Academic Publishers, Boston-London-Dordrecht, 2000.

[2] Ishibuchi, H. and Murata, T., and Gen, M, Performance Evaluation of Fuzzy Rule-Based Classification Systems Obtained by Multi-Objective Genetic Algorithms, Computers \& Industrial Engineering, Volume 35, Issues 3-4, 1998, pp. 575-578

[3] Ishibuchi, H., Nakashima T., and Morisawa T, Voting in Fuzzy Rule-Based Systems for Pattern Classification Problems, Fuzzy Sets and Systems, Volume 103, Issue 2, Soft Computing for Pattern Recognition, 1999, pp.223-238.

[4] Kuncheva, L. I, Fuzzy Classifier Design. Springer-Verlag, Heidelberg, 2000.

[5] Lei, Z., and Ren-hou, L, Designing of Classifiers Based on Immune Principles and Fuzzy Rules, Information Sciences, Volume 178, Issue 7, 2008, pp. 1836-1847.

[6] Li, T.-H., Guo N. R., and Kuo C.-L, Design of Adaptive Fuzzy Model for Classification Problem, Engineering Applications of Artificial Intelligence, Volume 18, Issue 3, 2005, pp. 297-306. 
[7] Roubos, J. A., Setnes M., and Abonyi J, Learning Fuzzy Classification Rules from Labeled Data, Information Sciences, Volume 150, Issues 1-2, 2003, 77-93.

[8] Sugeno, M, An Introductory Survey on Fuzzy Control. Information Sciences, 1985, 36:5983.

[9] Talašová, J, Fuzzy Methods of Multiple-Criteria Evaluation and Decision Making (in Czech). VUP, Olomouc, 2003.

[10] Talašová, J., and Stoklasa, J, Fuzzy Approach to Academic Staff Performance Evaluation. Proceedings of the $28^{\text {th }}$ International Conference on Mathematical Methods In Economics 2010, September 2010, České Budějovice, Czech Republic, pp. 621-626.

[11] Zadeh, L. A, Fuzzy Sets. Inform. Control, 8, pp. 338-353, 1965.

[12] Zadeh, L. A, The Concept of Linguistic Variable and Its Application to Approximate Reasoning. Information Sciences, Part 1: 8 (1975), 199-249, Part 2: 8 (1975), 301-357, Part 3: 9 (1975), 43-80, 1975.

[13] Zhou, E., and Khotanzad, A, Fuzzy Classifier Design Using Genetic Algorithms, Pattern Recognition, Volume 40, Issue 12, 2007, pp. 3401-3414.

[14] Leszek Rutkowski, Flexible Neuro-Fuzzy Systems: Structures, Learning and Performance Evaluation, Technical University of Czestochowa, Poland, Kluwer Academic Publishers New York, Chapter 2: Elements of The Theory of Fuzzy Sets.

[15] Jyh-Shing Roger Jang et al., Neuro-Fuzzy and Soft Computing, A Computational Approach to Learning and Machine Intelligence, First Edition, Prentice Hall, 1997, Chapter 2: Fuzzy Sets.

[16] Chandra Mohan M., Vijaya Kumar V. and Sujatha B, Classification of Child and Adult Based on Geometric Features of Face Using Linear Wavelets, IJSIP, Vol.1, No. 3, pp. 211-220, 2010.

[17] Chandra Mohan, Vijaya Kumar V. and Damodaram A, Adulthood Classification Based on Geometrical Facial Features, ICGST, 2009. 